\title{
INTRODUCTION TO THE SPECIAL ISSUE ON SMART SENSORS FOR SCALABLE COMPUTING
}

Various ICT applications, whether for city infrastructures, factories, or wearable devices, use large arrays of sensors collecting data for transmission over the Internet to a central, cloud-based computing resource. Analytics software running on the cloud computers reduces the huge volumes of generated data into actionable information for users, and commands to actuators back out in the field. So, smart sensors are one key factor in various ICT Application successes but these are not conventional types, which simply convert physical variables into electrical signals. They have needed to evolve into something more sophisticated to perform a technical, scalable and economical viable role within the ICT environment.

This special issue is devoted to the latest research in smart sensors for scalable computing in various application area such agriculture and Industries 4.0.

Ashish Kr. Luhach, The PNG Univeristy of Technology, Papua New Guinea Dharm Singh Jat, Namibia's University of Science and Technology, Namibia Kamarul Hawari bin Ghazali, Universiti Malaysia Pahang, Pekan, Malaysia 